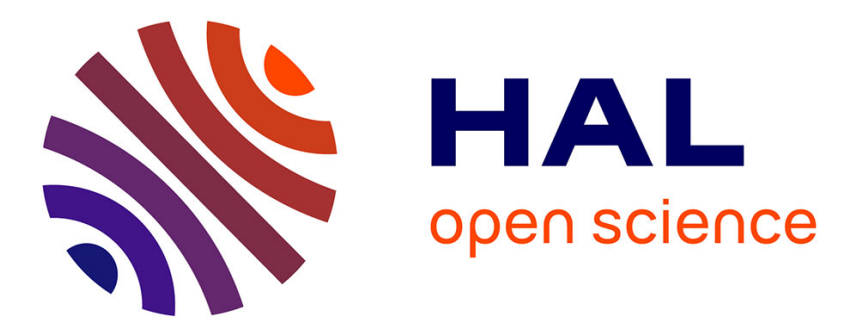

\title{
A One-Dimensional Coordination Polymer Assembled from a Macrocyclic Mn(III) Single-Molecule Magnet and Terephthalate
}

Sébastien Dhers, Rajni K Wilson, Mathieu Rouzières, Rodolphe Cleŕac, Sally Brooker, Rodolphe Clérac

\section{To cite this version:}

Sébastien Dhers, Rajni K Wilson, Mathieu Rouzières, Rodolphe Cleŕac, Sally Brooker, et al.. A OneDimensional Coordination Polymer Assembled from a Macrocyclic Mn(III) Single-Molecule Magnet and Terephthalate. Crystal Growth \& Design, 2020, 20 (3), pp.1538-1542. 10.1021/acs.cgd.9b01269 . hal-02890844

\section{HAL Id: hal-02890844 https://hal.science/hal-02890844}

Submitted on 24 Nov 2020

HAL is a multi-disciplinary open access archive for the deposit and dissemination of scientific research documents, whether they are published or not. The documents may come from teaching and research institutions in France or abroad, or from public or private research centers.
L'archive ouverte pluridisciplinaire HAL, est destinée au dépôt et à la diffusion de documents scientifiques de niveau recherche, publiés ou non, émanant des établissements d'enseignement et de recherche français ou étrangers, des laboratoires publics ou privés. 


\title{
A One-Dimensional Coordination Polymer Assembled from a Macrocyclic Mn(III) Single-Molecule Magnet and Terephthalate
}

\author{
Sébastien Dhers, Rajni K. Wilson, Mathieu Rouzières, Rodolphe Clérac,* and Sally Brooker*
}

Herein the strategy of deliberate assembly of stable soluble macrocyclic single-molecule magnets (SMMs), using appropriately chosen linkers to bridge the axial sites, as a controlled way of forming single-chain magnets (SCMs) is tested. First, the manganese(III) macrocyclic complex, $\left[\mathrm{Mn}^{\mathrm{III}}\left(\mathrm{L}^{\mathrm{Pr}}\right)(\mathrm{NCS})_{2}\right](1)$, of the monoanionic tetradentate equatorial-N4-donor macrocyclic $\left(\mathrm{L}^{\mathrm{Pr}}\right)^{-}$ligand (formed from $[1+1]$ Schiff base condensation of $2,2^{\prime}$-iminobisbenzaldehyde and dipropylenetriamine) is shown to be an SMM. Then, the 1:1 reaction of SMM 1 with sodium terephthalate linkers in $\mathrm{H}_{2} \mathrm{O} / \mathrm{DMF}$ is shown, by X-ray structure determination, to form dark red single crystals of the desired one-dimensional (1D) coordination polymer, $\left[\mathrm{Mn}^{\mathrm{III}}\left(\mathrm{L}^{\mathrm{Pr}}\right)(\mathrm{tpa})\right]_{n} \cdot n \mathrm{H}_{2} \mathrm{O}$. $0.5 n \operatorname{DMF}(2)$, of alternating dicationic macrocycles $\left[\mathrm{Mn}^{\mathrm{III}}\left(\mathrm{L}^{\mathrm{Pr}}\right)\right]^{2+}($ from 1$)$ linked by the bridging dianionic linkers [tpa $]^{2-}$. Despite having the desired structural features, magnetic measurements show that $\mathbf{2}$ is an SMM, not an SCM, as the coupling along the 1D coordination polymer is negligible (with $\Delta_{\mathrm{eff}} / \mathrm{k}_{\mathrm{B}}=13.7(5) \mathrm{K}$ and $\tau_{0}=1.4(5) \times 10^{-7} \mathrm{~s}$ ). Future attempts to use this strategy of linking macrocyclic SMMs together to access SCMs will clearly require the use of linkers that are able to more efficiently relay the magnetic information along the resulting chain. 
The field of molecular magnetism has been a rapidly expanding research area since the discovery in 1993 of the first singlemolecule magnet (SMM), ${ }^{1,2}$ and in 2001 of the first onedimensional (1D) analogue, ${ }^{3}$ subsequently named a singlechain magnet (SCM). ${ }^{4}$ Several SCMs have shown promising results, and multifunctional SCMs have also been reported. ${ }^{5-21}$ SMM and SCM compounds are therefore attractive objects for fundamental studies, for example, to explore quantum effects, and for potential applications, such as data storage. ${ }^{22,2.3}$

Our approach to SMMs has been to use macrocyclic ligands to provide control and fine-tuning of the metal ion environments, ${ }^{24-29}$ as well as to confer stability and processability on our systems. ${ }^{30-35}$ Following from this, our strategy for accessing $\mathrm{SCMs}^{33}$ has been to link these macrocyclic SMMs into chains, as a similar approach has been proven to generate SCMs. ${ }^{36}$ Of course, the formation of a chain does not guarantee SCM behavior, and unfortunately this was the problem in the case of the systems prepared from our tetrametallic $3 \mathrm{~d}-4 \mathrm{f}$ macrocyclic $\left[\mathrm{Cu}_{3}{ }_{3} \mathrm{~Tb}^{\mathrm{III}}\right]$ SMM building blocks. ${ }^{30,35,37}$ Nevertheless, the macrocyclic approach provides both enhanced stability and more control over the resulting molecular architectures than noncyclic analogues can, so herein a monometallic $\mathrm{Mn}$ (III) macrocyclic complex, $\left[\mathrm{Mn}^{\mathrm{III}}\left(\mathrm{L}^{\mathrm{Pr}}\right)(\mathrm{NCS})_{2}\right](1)$, reported earlier, ${ }^{34}$ has been reinvestigated and found to exhibit slow relaxation of the magnetization. Manganese(III) is usually Jahn-Teller distorted so it provides the required uniaxial anisotropy for 
creating a thermal energy barrier that is essential to observe SMM and SCM properties. The organization of these $\mathrm{Mn}(\mathrm{III})$ building blocks into $1 \mathrm{D}$ coordination polymers often helps to align all the distortion axes, that correspond to local easy axes of anisotropy, along a unique direction, and thus may induce SCM properties when the intrachain magnetic interactions are significant. ${ }^{38}$ Hence, 1 was chosen for use as a new anisotropic building block, and a terephthalate dianion, $[\mathrm{tpa}]^{2-}$, was chosen as a potentially linear linker (Scheme 1). Although no

Scheme 1. Schematic View of the Building Block Moieties: the Dication $\left[\mathrm{Mn}^{\mathrm{III}}\left(\mathrm{L}^{\mathrm{Pr}}\right)\right]^{2+}$ Building Block of 1 (Left) and the Dianion Linker $[\text { tpa }]^{2-}$ (Right)
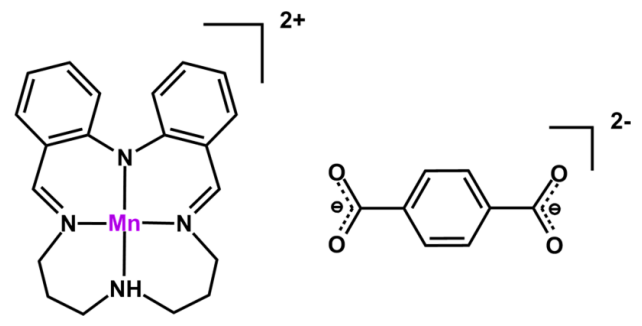

SCMs have been reported using $[\mathrm{tpa}]^{2-}$ as a linker, a related dianion, pyridine-2,5-dicarboxylate, 2,5-pydc ${ }^{2-}$, has been used, by Gao and co-workers, in the synthesis of $1 \mathrm{D}$ coordination polymers $\left[\mathrm{Ln}_{2} \mathrm{Co}_{2}(2,5-\text { pydc })_{6}\left(\mathrm{H}_{2} \mathrm{O}\right)_{4}\right]_{n} \cdot 2 n \mathrm{H}_{2} \mathrm{O}(\mathrm{Ln}=\mathrm{Dy}$ or $\mathrm{Tb})$ claimed to behave like SCMs.

The 1D-coordination polymer $\left[\mathrm{Mn}^{\mathrm{III}}\left(\mathrm{L}^{\mathrm{Pr}}\right)(\mathrm{tpa})_{2}\right]_{n}$ (2) was obtained by slow liquid-liquid diffusion together of the two reagent solutions (in 1:1 $\left.\mathrm{H}_{2} \mathrm{O} / \mathrm{DMF}\right),\left[\mathrm{Mn}^{\mathrm{III}}\left(\mathrm{L}^{\mathrm{Pr}}\right)(\mathrm{NCS})_{2}\right]$ $(1)^{34}$ and $\mathrm{Na}_{2}[$ tpa $]$. Dark red crystals of $\left[\mathrm{Mn}^{\mathrm{III}}\left(\mathrm{L}^{\mathrm{Pr}}\right)(\mathrm{tpa})\right]_{n}$. $n \mathrm{H}_{2} \mathrm{O} \cdot 0.5 n \mathrm{DMF}$ (2) were obtained over a few days, and more formed over the next few weeks (yield 31\%).

A single crystal X-ray structure determination on 2 (Figures 1 and S1 and S2; Tables 1 and S1) confirms the 1:1 assembly

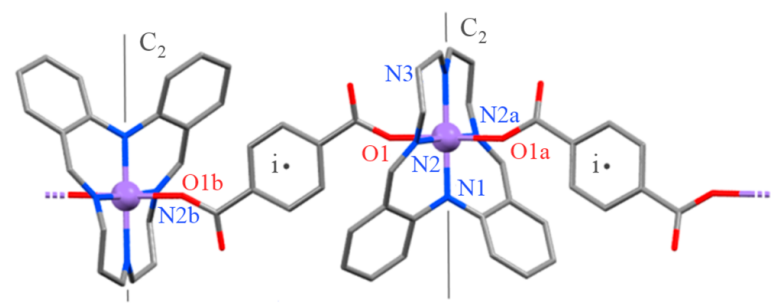

Figure 1. Perspective view of the 1D coordination polymer (chain) $\left[\mathrm{Mn}^{\mathrm{III}}\left(\mathrm{L}^{\mathrm{Pr}}\right)(\mathrm{tpa})\right]_{n} \cdot n \mathrm{H}_{2} \mathrm{O} \cdot 0.5 n \mathrm{DMF}$ (2). All hydrogen atoms and noncoordinating solvent molecules are omitted for clarity. Color code: $\mathrm{Mn}$ (violet), O (red), N (blue), and C (gray). Symmetry operations: $\mathrm{a}=2$-fold axis $\left(\mathrm{C}_{2}\right)$ running through $\mathrm{N} 1-\mathrm{Mn} 1-\mathrm{N} 3$, and $\mathrm{b}=$ center of inversion (i) located in the middle of the terephthalate ring.

of a 1D polymer of alternating dicationic macrocycles $\left[\mathrm{Mn}^{\mathrm{III}}\left(\mathrm{L}^{\mathrm{Pr}}\right)\right]^{2+}$ (from 1) with dianionic linkers $[\mathrm{tpa}]^{2-}$. The chain crystallizes in the monoclinic space group $P 2 / n$ with half a $\mathrm{Mn}(\mathrm{III})$ macrocycle and half a $[\mathrm{tpa}]^{2-}$ in the asymmetric unit, as well as a disordered water molecule $(0.75: 0.25)$ and a half occupancy DMF molecule. The other half of the
Table 1. Comparison of Range and Average Lengths $(\AA)$ of $\mathrm{Mn}-\mathrm{X}$ Bonds $\left(\mathrm{X}_{\text {axial }}\right.$ is $\mathrm{N}$ for $\mathbf{1}$ and $\mathrm{O}$ for 2$)$, Selected Angles

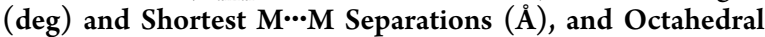
Axial Elongation Parameters ${ }^{a}$ for Both the Building Block (1) and the Resulting 1D Polymer (2)

\begin{tabular}{lll}
\multicolumn{1}{c}{ parameters } & \multicolumn{1}{c}{ macrocycle (1) } & \multicolumn{1}{c}{1 1D polymer (2) } \\
$\mathrm{Mn}-\mathrm{N}_{\text {amino }}$ & $1.922(7), 1.913(7)$ & $1.958(6)$ \\
$\mathrm{Mn}-\mathrm{N}_{\text {imine }}$ & $2.00(8)-2.031(7)$ & $2.041(4)$ \\
$\mathrm{Mn}-\mathrm{N}_{\text {amine }}$ & $2.087(7), 2.101(8)$ & $2.075(7)$ \\
$\mathrm{Mn}-\mathrm{N}_{\mathrm{eq}}$ & $1.913-2.101$ (av. 2.012) & $1.958-2.075$ (av. 2.029) \\
$\mathrm{Mn}-\mathrm{X}_{\text {axial }}$ & $2.203-2.230$ (av. 2.218) & 2.151 \\
$\mathrm{~T}^{40}$ & 0.91 & 0.94 \\
$\mathrm{X}_{\text {axial }}-\mathrm{Mn}-\mathrm{X}_{\text {axial }}$ & $176.0(3)-178.8(3)$ & $177.8(2)$ \\
$\mathrm{Mn} \cdots \mathrm{Mn}$ (intrachain) & & 11.418 \\
$\mathrm{Mn} \cdots \mathrm{Mn}$ (interchain) & 7.976 & 7.854
\end{tabular}

${ }^{a_{T}}=$ average in plane $\mathrm{Cu}-\mathrm{N}$ divided by average axial $\mathrm{Cu}-\mathrm{X} ; \mathrm{T}<1$ for axial elongation vs $T>1$ for axial compression. ${ }^{40}$

macrocycle is generated by a 2 -fold axis that runs through $\mathrm{N} 1-\mathrm{Mn} 1-\mathrm{N} 3$, and the other half of the $[\mathrm{tpa}]^{2-}$ is generated by an inversion center located in the middle of the terephthalate ring.

The monoanionic tetradentate macrocyclic ligand provides an equatorial plane to the $\mathrm{Mn}(\mathrm{III})$ center, comprising one amino, one amine, and two Schiff base nitrogen donors (Table 1). The shortest $\mathrm{Mn}-\mathrm{N}$ bond involves the deprotonated amino nitrogen atom $(\mathrm{Mn}-\mathrm{N} 11.958 \AA$ ), while the longest is to the neutral amine nitrogen atom $(\mathrm{Mn}-\mathrm{N} 32.075 \AA)$. The $\mathrm{N}_{4} \mathrm{O}_{2}$ coordination of the $\mathrm{Mn}(\mathrm{III})$ centers is completed by two trans coordinated monodentate $[\mathrm{tpa}]^{2-}$ anions, which link the complexes in the chain together. As expected for a $\mathrm{Mn}$ (III) metal ion, Jahn-Teller elongation is observed, and it occurs along the $\mathrm{Mn}-\mathrm{O}$ bonds of these terephthalate linkers $(\mathrm{Mn}-$ O1 $2.151 \AA)$, resulting in a tetragonal elongation $(T=0.94){ }^{40}$

Herein the magnetic properties of the 1D compound 2 are investigated, and those of the $\mathrm{Mn}$ (III) building block, $\left[\mathrm{Mn}^{\mathrm{III}}\left(\mathrm{L}^{\mathrm{Pr}}\right)(\mathrm{NCS})_{2}\right], 1$ have been reinvestigated to check for slow relaxation of the magnetization. The $\chi T$ product is 3.1 $\mathrm{cm}^{3} \mathrm{~K} \mathrm{~mol}^{-1}$ for both $\mathbf{1}$ and $\mathbf{2}$ at room temperature (Figure 2), which is in excellent agreement with the expected value for one manganese(III) ion ( $S=2 ; g=2 ; C=3.0 \mathrm{~cm}^{3} \mathrm{~K} \mathrm{~mol}^{-1}$ ).

Along the chain, each $\left[\mathrm{Mn}^{\mathrm{III}}\left(\mathrm{L}^{\mathrm{Pr}}\right)\right]^{2+}$ macrocyclic unit is linked to the next by a bis-monodentate bridging terephthalate linker, forming the $1 \mathrm{D}$ coordination polymer. Because of the inversion symmetry at the centroid of the linkers, the macrocycles alternate up and down along the chain direction. The 1D polymers pack together efficiently via classical $\mathrm{O}-\mathrm{H}$ bonds involving the water of crystallization $(\mathrm{O} 30-\mathrm{O} 2=2.952$ $\AA$ and $\mathrm{O} 30-\mathrm{O} 50=2.732 \AA$ ) and nonclassical $\mathrm{C}-\mathrm{H}$-bond interactions, some of which involve the DMF of crystallization, $\mathrm{O} 50\left(\mathrm{C}^{\prime}-\mathrm{O} 2=3.422 \AA\right.$ and $\left.\mathrm{C}^{\prime}-\mathrm{O} 50=3.096 \AA\right)$, resulting in a $3 \mathrm{D}$ supramolecular network (Figures S1 and S2, Supporting Information). Unsurprisingly, the $\mathrm{Mn} \cdots \mathrm{Mn}$ separation is significantly shorter between chains $(7.854 \AA)$ than within a chain $(11.418 \AA$ ).

Upon lowering the temperature, the $\chi T$ product is roughly constant until around $50 \mathrm{~K}(1)$ and $40 \mathrm{~K}(2)$, respectively, when it starts to decrease, reaching minimum values of $1.6(1)$ and $2.1(2) \mathrm{cm}^{3} \mathrm{~K} \mathrm{~mol}^{-1}$ at $1.85 \mathrm{~K}$, consistent with the possible combined effects of the magnetic anisotropy intrinsic to $\mathrm{Mn}$ (III) metal ions and antiferromagnetic interactions between the macrocyclic units. Using an anisotropic spin Heisenberg 


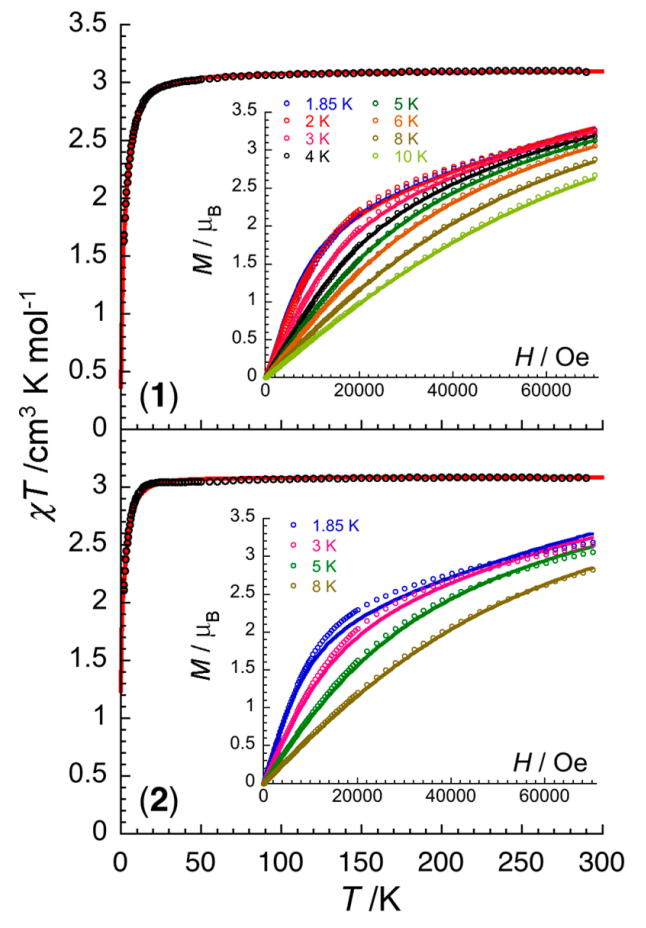

Figure 2. Temperature dependence of the $\chi T$ product (where $\chi$ is the molar magnetic susceptibility that equals $M / H$ per complex) collected in an applied dc magnetic field of $0.1 \mathrm{~T}$ for 1 (top) and 2 (bottom). Inset: Field dependence of the magnetization for $\mathbf{1}$ (top) and $\mathbf{2}$ (bottom) below 10 and $8 \mathrm{~K}\left(8-200 \mathrm{mT} \mathrm{min}^{-1}\right)$, respectively. The solid lines are the best fits to the model described in the text.

Hamiltonian $\left(\boldsymbol{H}=D S_{\mathrm{Mn}, \mathrm{z}}{ }^{2}\right)$ and the analytical expression of the magnetization estimated by applying the van Vleck equation ${ }^{41,42}$ in the weak field approximation, ${ }^{43,44}$ the susceptibility and magnetization data could be fitted with $S=2, g=2.03(2)$, $D / k_{\mathrm{B}}=-5.0(1) \mathrm{K}$ and, for $1 z J / k_{\mathrm{B}}=-0.25(2) \mathrm{K}$, whereas for $2 z J / k_{\mathrm{B}}=-0.04(1) \mathrm{K}$. Interestingly, the antiferromagnetic coupling $(J)$ is weaker for the $1 \mathrm{D}$ compound 2 than for the isolated macrocycle 1, indicating that, unfortunately, the $[\text { tpa }]^{2-}$ linker separates the $\left[\mathrm{Mn}^{\mathrm{III}}\left(\mathrm{L}^{\mathrm{Pr}}\right)\right]^{2+}$ complexes more efficiently. Both of these fits indicate the presence of the expected magnetic anisotropy of the $\mathrm{Mn}$ (III) ion, which is confirmed by the field dependence of the magnetization as the $M$ versus $H / T$ curves do not superimpose at high fields (Figure 2 insets, and Figures S3 and S6, Supporting Information).

The ac susceptibility of macrocyclic Mn(III) building block 1 was measured to check for possible slow relaxation of the magnetization. At $1.85 \mathrm{~K}$, there was no out-of-phase component $\left(\chi^{\prime \prime}\right)$ without an external field applied (Figure S4, Supporting Information). However, when an external dc field is applied, an out-of-phase component is observed (Figure S5, Supporting Information), indicating the presence of slow relaxation of the magnetization in the 1 unit. Unfortunately, the relaxation modes are not visible in the temperature/ac frequency window of measurement, so the slow relaxation time could not be quantified. However, it is promising to see that this new building block is an SMM.

The ac susceptibility of the chain $\mathbf{2}$ was also measured to check for possible slow relaxation of the magnetization. At 1.85 $\mathrm{K}$, there was no $\chi^{\prime \prime}$ component without an external field applied (Figures S7 and S8, Supporting Information).
However, when an external dc field is applied, an out-ofphase component $\left(\chi^{\prime \prime}\right)$ is observed (Figure 3 ), indicating the

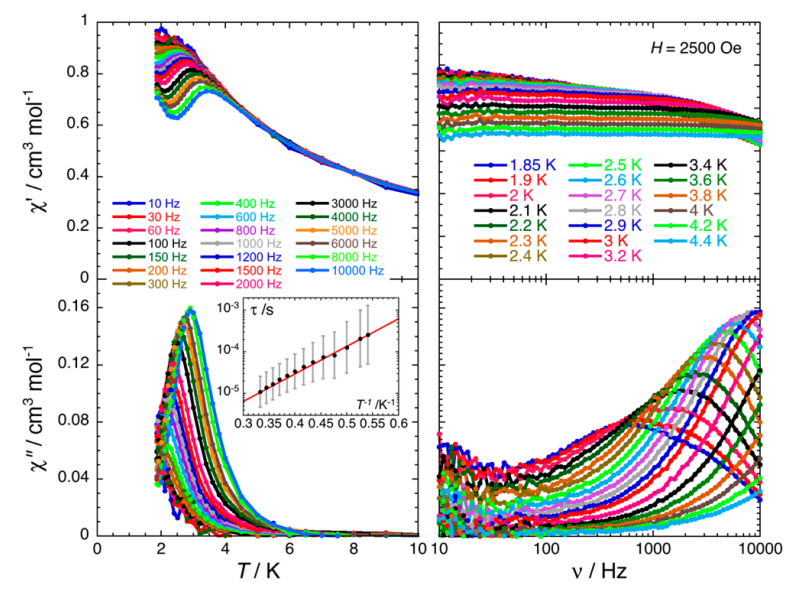

Figure 3. Frequency (left) and temperature (right) dependences of the real ( $\chi^{\prime}$, top) and imaginary ( $\chi^{\prime \prime}$, bottom) parts of the ac susceptibility, between 1.85 and $10 \mathrm{~K}$ and between 10 and $10000 \mathrm{~Hz}$, for $\mathbf{2}$ in a 2500-Oe dc field. Solid lines are visual guides. Inset (bottom left): $\tau$ vs $T^{-1}$ plot at a $2500-O e$ dc field from the generalized Debye fit of the frequency dependence of the imaginary part of the ac susceptibility $\left(\chi^{\prime \prime}\right.$; error bars on the relaxation time have be calculated from the $\alpha$ parameters of the generalized Debye fit and the log-normal distribution; see ref 45). The solid red line is the best fit to the Arrhenius law.

presence of slow relaxation of the magnetization, due to the presence of $\left[\mathrm{Mn}{ }^{\mathrm{III}}\left(\mathrm{L}^{\mathrm{Pr}}\right)\right]^{2+}$ unit (analogous to 1 ) in the chain. This time, the relaxation modes are clearly visible in the window of measurement, so the slow relaxation of the magnetization can be quantified, fitting the ac susceptibility data by a generalized Debye model. The temperature dependence of the relaxation time can be fitted to an Arrhenius law with $\Delta_{\text {eff }} / k_{\mathrm{B}}=15(2) \mathrm{K}$ and $\tau_{0}=7(2) \times 10^{-8}$ $\mathrm{s}$ (Figure 3, bottom left, Inset). While this compound is a chain from a structural point of view, the observed slow dynamics of the magnetization cannot be attributed to an SCM behavior as the magnetic interactions between the $\mathrm{Mn}$ (III) centers through end-to-end terephthalate bridges along the chain are unfortunately negligible, as shown by the analysis of the $\mathrm{dc}$ susceptibility (vide supra) and previously reported systems. ${ }^{46}$ This compound is thus an SMM and not an SCM. Interestingly $\mathbf{2}$ is a "better" SMM than $\mathbf{1}$, as for $\mathbf{1}$ the relaxation modes were not visible in the experimental window of measurement.

In conclusion, the ac susceptibility of the $\mathrm{Mn}$ (III) macrocycle 1 was measured and revealed that it has potential for use as an SMM building block in the synthesis of SCMs. As a first step to test its coordination ability, it has been combined with a terephthalate linker, giving single crystals of the desired 1D coordination polymer 2 . The structure determination showed that the dianionic linker has efficiently aligned the SMM building blocks along the chain, but the magnetic characterization shows that it has not effectively relayed the magnetic information along the 1D chain, leading to magnetically isolated $\mathrm{Mn}(\mathrm{III})$ centers. The SMM properties of the macrocyclic $\mathrm{Mn}$ (III) unit in this $1 \mathrm{D}$ compound have been fully characterized leading to the conclusion that the relaxation time follows a thermally activated process with $\Delta_{\text {eff }} /$ 
$k_{\mathrm{B}}=15(2) \mathrm{K}$ and $\tau_{0}=7(2) \times 10^{-8} \mathrm{~s}$. While compound 2 is not an SCM, it is an SMM, and more importantly the potential of the $\left[\mathrm{Mn}{ }^{\mathrm{III}}\left(\mathrm{L}^{\mathrm{Pr}}\right)\right]^{2+} \mathrm{SMM}$ building block (1) for SCM synthesis is clear and should be pursued further in the future, but utilizing linkers that can more efficiently relay the magnetic information along the resulting $1 \mathrm{D}$ coordination polymer.
We are grateful for the support by grants from the University of Otago (including a Ph.D. scholarship for R.K.W.) and the MacDiarmid Institute for Advanced Materials and Nanotechnology (including a Ph.D. scholarship for S.D.). We also thank the University of Bordeaux, the CNRS, the Conseil Régional de Nouvelle Aquitaine, the MOLSPIN COST action CA15128, the GdR MCM-2: Magnétisme et Commutation Moléculaires and the Dumont d'Urville NZ-France Science \& Technology Support Programme $\left(N^{\circ} 23793 \mathrm{PH}\right)$.
(1) Sessoli, R.; Gatteschi, D.; Caneschi, A.; Novak, M. A. Magnetic bistability in a metal-ion cluster. Nature 1993, 365, 141-143.

(2) Sessoli, R.; Tsai, H.-L.; Schake, A. R.; Wang, S.; Vincent, J. B.; Folting, K.; Gatteschi, D.; Christou, G.; Hendrickson, D. N. HighSpin Molecules: $\left[\mathrm{Mn}_{12} \mathrm{O}_{12}\left(\mathrm{O}_{2} \mathrm{CR}\right)_{16}\left(\mathrm{H}_{2} \mathrm{O}\right)_{4}\right]$. J. Am. Chem. Soc. 1993, 115, 1804-1816.

(3) Caneschi, A.; Gatteschi, D.; Lalioti, N.; Sangregorio, C.; Sessoli, R.; Venturi, G.; Vindigni, A.; Rettori, A.; Pini, M. G.; Novak, M. A. Cobalt(II)-nitronyl nitroxide chains as molecular magnetic nanowires. Angew. Chem., Int. Ed. 2001, 40, 1760-1763.

(4) Clérac, R.; Miyasaka, H.; Yamashita, M.; Coulon, C. Evidence for Single-Chain Magnet behavior in a $\mathrm{Mn}^{\mathrm{III}}-\mathrm{Ni}^{\mathrm{II}}$ chain designed with high spin magnetic units: a route to high temperature metastable magnets. J. Am. Chem. Soc. 2002, 124, 12837-12844.

(5) Lescouezec, R.; Vaissermann, J.; Ruiz-Perez, C.; Lloret, F.; Carrasco, R.; Julve, M.; Verdaguer, M.; Dromzee, Y.; Gatteschi, D.; Wernsdorfer, W. Cyanide-Bridged Iron(III)-Cobalt(II) Double Zigzag Ferromagnetic Chains: Two New Molecular Magnetic Nanowires. Angew. Chem. 2003, 115, 1521-1524.

(6) Wang, S.; Zuo, J.-L.; Gao, S.; Song, Y.; Zhou, H.-C.; Zhang, Y.Z.; You, X.-Z. The Observation of Superparamagnetic Behavior in Molecular Nanowires. J. Am. Chem. Soc. 2004, 126, 8900-8901.

(7) Xu, H.-B.; Wang, B.-W.; Pan, F.; Wang, Z.-M.; Gao, S. Stringing Oxo-Centered Trinuclear $\left[\mathrm{Mn}_{3}{ }_{3} \mathrm{O}\right]$ Units into Single-Chain Magnets with Formate or Azide Linkers. Angew. Chem., Int. Ed. 2007, 46, $7388-7392$.

(8) Miyasaka, H.; Saitoh, A.; Yamashita, M.; Clérac, R. A Mn ${ }_{2}{ }_{2}{ }^{\mathrm{II}}{ }^{\mathrm{II}}$ single-chain magnet separated by a thick isolating network of $\mathrm{BPh}_{4}{ }^{-}$ anions. Dalton Trans. 2008, 2422-2427.

(9) Ouellette, W.; Prosvirin, A. V.; Whitenack, K.; Dunbar, K. R.; Zubieta, J. A Thermally and Hydrolytically Stable Microporous Framework Exhibiting Single-Chain Magnetism: Structure and Properties of $\left[\mathrm{Co}_{2}\left(\mathrm{H}_{0.67} \text { bdt }\right)_{3}\right] \cdot 20 \mathrm{H}_{2} \mathrm{O}$. Angew. Chem., Int. Ed. 2009, 48, 2140-2143.

(10) Miyasaka, H.; Takayama, K.; Saitoh, A.; Furukawa, S.; Yamashita, M.; Clérac, R. Three-dimensional antiferromagnetic order of Single-Chain Magnets: a new approach to design moleculebased magnets. Chem. - Eur. J. 2010, 16, 3656-3662.

(11) Hoshino, N.; Sekine, Y.; Nihei, M.; Oshio, H. Achiral single molecule magnet and chiral single chain magnet. Chem. Commun. 2010, 46, 6117-6119.

(12) Liu, T.; Zhang, Y.-J.; Kanegawa, S.; Sato, O. Photoinduced Metal-to-Metal Charge Transfer toward Single-Chain Magnet. J. Am. Chem. Soc. 2010, 132, 8250-8251.

(13) Harris, T. D.; Bennett, M. V.; Clérac, R.; Long, J. R. $\left[\mathrm{ReCl}_{4}(\mathrm{CN})_{2}\right]^{2-}$ : A High Magnetic Anisotropy Building Unit Giving Rise to the Single-Chain Magnets (DMF) ${ }_{4} \mathrm{MReCl}_{4}(\mathrm{CN})_{2}(\mathrm{M}=\mathrm{Mn}$, $\mathrm{Fe}, \mathrm{Co}, \mathrm{Ni})$. J. Am. Chem. Soc. 2010, 132, 3981.

(14) Feng, X.; David Harris, T.; Long, J. R. Influence of structure on exchange strength and relaxation barrier in a series of $\mathrm{Fe}^{\mathrm{II}} \mathrm{Re}^{\mathrm{IV}}(\mathrm{CN})^{2}$ single-chain magnets. Chem. Sci. 2011, 2, 1688-1694.

(15) Yoon, J. H.; Ryu, D. W.; Choi, S. Y.; Kim, H. C.; Koh, E. K.; Tao, J.; Hong, C. S. Spin crossover in the cyanide-bridged $\mathrm{Mo}^{\mathrm{V}} \mathrm{Mn}^{\mathrm{III}}$ single-chain magnet containing $\mathrm{Fe}^{\mathrm{II}}$ cations. Chem. Commun. 2011, 47, 10416-10418.

(16) Nather, C.; Boeckmann, J. A rational route to SCM materials based on a 1-D cobalt selenocyanato coordination polymer. Chem. Commun. 2011, 47, 7104-7106.

(17) Dong, D.-P.; Liu, T.; Kanegawa, S.; Kang, S.; Sato, O.; He, C.; Duan, C.-Y. Photoswitchable Dynamic Magnetic Relaxation in a WellIsolated $\left\{\mathrm{Fe}_{2} \mathrm{Co}\right\}$ Double-Zigzag Chain. Angew. Chem., Int. Ed. 2012, 51, 5119-5123.

(18) Senapati, T.; Pichon, C.; Ababei, R.; Mathonière, C.; Clérac, R. Cyanido-Bridged $\mathrm{Fe}(\mathrm{III})-\mathrm{Mn}$ (III) Heterobimetallic Materials Built From $\mathrm{Mn}(\mathrm{III})$ Schiff Base Complexes and Di- or Tri-Cyanido Fe(III) Precursors. Inorg. Chem. 2012, 51, 3796-3812.

(19) Miyasaka, H.; Madanbashi, T.; Saitoh, A.; Motokawa, N.; Ishikawa, R.; Yamashita, M.; Bahr, S.; Wernsdorfer, W.; Clérac, R. 
Cyano-Bridged $\mathrm{Mn}^{\mathrm{III}}-\mathrm{M}^{\mathrm{III}}$ Single-Chain Magnets with $\mathrm{M}^{\mathrm{III}}=\mathrm{Co}^{\mathrm{III}}, \mathrm{Fe}^{\mathrm{III}}$, $\mathrm{Mn}^{\mathrm{III}}$, and $\mathrm{Cr}^{\mathrm{III}}$. Chem. - Eur. J. 2012, 18, 3942-3954.

(20) Zhang, W.-X.; Shiga, T.; Miyasaka, H.; Yamashita, M. New Approach for Designing Single-Chain Magnets: Organization of Chains via Hydrogen Bonding between Nucleobases. J. Am. Chem. Soc. 2012, 134, 6908-6911.

(21) Chorazy, S.; Nakabayashi, K.; Imoto, K.; Mlynarski, J.; Sieklucka, B.; Ohkoshi, S.-i. Conjunction of Chirality and Slow Magnetic Relaxation in the Supramolecular Network Constructed of Crossed Cyano-Bridged $\mathrm{Co}^{\mathrm{II}}-\mathrm{W}^{\mathrm{V}}$ Molecular Chains. J. Am. Chem. Soc. 2012, 134, 16151-16154.

(22) Leuenberger, M. N.; Loss, D. Quantum computing in molecular magnets. Nature 2001, 410, 789-793.

(23) Jeon, I.-R.; Clérac, R. Controlled association of single-molecule magnets (SMMs) into coordination networks: towards a new generation of magnetic materials. Dalton Trans. 2012, 41, 9569-9586.

(24) Feltham, H. L. C.; Clérac, R.; Ungur, L.; Vieru, V.; Chibotaru, L. F.; Powell, A. K.; Brooker, S. Synthesis and magnetic properties of a new family of macrocyclic $\mathrm{M}_{3}^{\mathrm{II}} \mathrm{L} \mathrm{n}^{\mathrm{III}}$ complexes: insights into the effect of subtle chemical modification on Single Molecule Magnet behavior. Inorg. Chem. 2012, 51, 10603-10612.

(25) Feltham, H. L. C.; Lan, Y.; Klöwer, F.; Ungur, L.; Chibotaru, L. F.; Powell, A. K.; Brooker, S. A non-sandwiched macrocyclic monolanthanide single molecule magnet: the key role of axiality. Chem. Eur. J. 2011, 17, 4362-4365.

(26) Feltham, H. L. C.; Clérac, R.; Powell, A. K.; Brooker, S. A tetranuclear, macrocyclic 3d-4f complex showing Single-Molecule Magnet behaviour. Inorg. Chem. 2011, 50, 4232-4234.

(27) Feltham, H. L. C.; Dhers, S.; Rouzières, M.; Clérac, R.; Powell, A. K.; Brooker, S. A family of fourteen stable soluble macrocyclic $\left[\mathrm{Ni}^{\mathrm{II}}{ }_{3} \mathrm{Ln}^{\mathrm{III}}\right]$ complexes. Inorg. Chem. Front. 2015, 2, 982-990.

(28) Feltham, H. L. C.; Brooker, S. Review of purely $4 \mathrm{f}$ and mixedmetal nd-4f Single-Molecule Magnets containing only one lanthanide ion. Coord. Chem. Rev. 2014, 276, 1-33.

(29) Feltham, H. L. C.; Clérac, R.; Ungur, L.; Chibotaru, L. F.; Powell, A. K.; Brooker, S. By design: a macrocyclic 3d-4f SingleMolecule Magnet with quantifiable zero-field slow relaxation of magnetization. Inorg. Chem. 2013, 52, 3236-3240.

(30) Dhers, S.; Feltham, H. L. C.; Rouzières, M.; Clérac, R.; Brooker, S. Discrete vs Chain Assembly: Hexacyanometallate Linkers and Macrocyclic \{3d-4f\} Single-Molecule Magnet Building Blocks. Inorg. Chem. 2019, 58, 5543-5554.

(31) Feltham, H. L. C.; Dumas, C.; Mannini, M.; Otero, E.; Sainctavit, P.; Sessoli, R.; Meledandri, C. J.; Brooker, S. Proof of principle: immobilisation of robust $\mathrm{Cu}_{3}{ }_{3} \mathrm{~Tb}^{\mathrm{III}}$ macrocycles on small suitably pre-functionalised gold nanoparticles. Chem. - Eur. J. 2017, 23, 2517-2521.

(32) Dhers, S.; Feltham, H. L. C.; Rouzières, M.; Clérac, R.; Brooker, S. Macrocyclic \{3d-4f\} SMMs as building blocks for 1Dpolymers: selective bridging of $4 \mathrm{f}$ ions by use of an O-donor ligand. Dalton Trans. 2016, 45, 18089-18093.

(33) Dhers, S.; Feltham, H. L. C.; Brooker, S. A toolbox of building blocks, linkers and crystallisation methods used to generate SingleChain Magnets. Coord. Chem. Rev. 2015, 296, 24-44.

(34) Wilson, R. K.; Dhers, S.; Sproules, S.; McInnes, E. J. L.; Brooker, S. Three manganese complexes of anionic N4-donor Schiffbase macrocycles: monomeric $\mathrm{Mn}(\mathrm{II})$ and $\mathrm{Mn}(\mathrm{III})$, and dimeric $\mathrm{Mn}(\mathrm{IV})$. Aust. J. Chem. 2019, 72, 805-810.

(35) Dhers, S.; Feltham, H. L. C.; Clérac, R.; Brooker, S. Design of one-dimensional coordination networks from a macrocyclic $\{3 \mathrm{~d}-4 \mathrm{f}\}$ Single-Molecule Magnet precursor linked by $\left[\mathrm{W}(\mathrm{CN})_{8}\right]^{3-}$ anions. Inorg. Chem. 2013, 52, 13685-13691.

(36) Ferbinteanu, M.; Miyasaka, H.; Wernsdorfer, W.; Nakata, K.; Sugiura, K.-i.; Yamashita, M.; Coulon, C.; Clérac, R. Single-Chain Magnet $\left(\mathrm{NEt}_{4}\right)\left[\mathrm{Mn}_{2}(5-\mathrm{MeOsalen})_{2} \mathrm{Fe}(\mathrm{CN})_{6}\right]$ made of $\mathrm{Mn}^{\mathrm{III}}-\mathrm{Fe}^{\mathrm{III}}$ $\mathrm{Mn}^{\text {III }}$ trinuclear Single-Molecule Magnet with an $\mathrm{S}_{\mathrm{T}}=9 / 2$ spin ground state. J. Am. Chem. Soc. 2005, 127, 3090-3099.

(37) Dhers, S.; Feltham, H. L. C.; Rouzieres, M.; Clerac, R.; Brooker, S. Macrocyclic \{3d-4f\} SMMs as building blocks for 1D- polymers: selective bridging of $4 \mathrm{f}$ ions by use of an O-donor ligand. Dalton Trans. 2016, 45, 18089-18093.

(38) Miyasaka, H.; Saitoh, A.; Abe, S. Magnetic assemblies based on Mn(III) salen analogues. Coord. Chem. Rev. 2007, 251, 2622-2664.

(39) Huang, Y.-G.; Wang, X.-T.; Jiang, F.-L.; Gao, S.; Wu, M.-Y.; Gao, Q.; Wei, W.; Hong, M.-C. Cobalt-Lanthanide Coordination Polymers Constructed with Metalloligands: A Ferromagnetic Coupled Quasi-1D Dy ${ }^{3+}$ Chain Showing Slow Relaxation. Chem. - Eur. J. 2008, 14, 10340-10347.

(40) Hathaway, B.; Tomlinson, A. A. G. Copper(II) ammonia complexes. Coord. Chem. Rev. 1970, 5, 1-43.

(41) van Vleck, J. H. The Theory of Electric and Magnetic Susceptibility; Oxford University Press: London, 1932.

(42) Boča, R. Theoretical foundations of Molecular Magnetism; Elsevier: Lausanne (Switzerland), 1999; Chapter 8.

(43) Myers, B. E.; Berger, L.; Friedberg, S. Low-Temperature Magnetization of $\mathrm{Cu}\left(\mathrm{NO}_{3}\right)_{2} \cdot 2.5 \mathrm{H}_{2} \mathrm{O}$. J. Appl. Phys. 1969, 40, 11491151.

(44) O'Connor, C. J. Prog. Inorg. Chem.; Lippard, S. J., Ed.; Wiley \& Sons: New York, 1982; Vol. 29, p 203.

(45) Reta, D.; Chilton, N. F. Uncertainty estimates for magnetic relaxation times and magnetic relaxation parameters. Phys. Chem. Chem. Phys. 2019, 21, 23567-23575.

(46) Sun, D.; Cao, R.; Liang, Y.; Shi, Q.; Su, W.; Hong, M. Hydrothermal syntheses, structures and properties of terephthalatebridged polymeric complexes with zig-zag chain and channel structures. J. Chem. Soc., Dalton Trans. 2001, 2335-2340. 